Abstract THU0386 - Table 1. Patient characteristics of Chilean axSpA patients ( $n=472$ ).

\begin{tabular}{|c|c|c|c|c|c|c|c|}
\hline & $\begin{array}{l}\text { Overall } \\
\qquad(n= \\
472)\end{array}$ & $\begin{array}{l}\text { Men } \\
(\mathrm{n}= \\
173)\end{array}$ & $\begin{array}{c}\text { Women } \\
\qquad \begin{array}{c}(n= \\
299)\end{array}\end{array}$ & $p=$ & $\begin{array}{c}\text { Biologics } \\
(n=92)\end{array}$ & $\begin{array}{c}\text { No } \\
\text { Biologics } \\
(n=372)\end{array}$ & $\mathrm{p}=$ \\
\hline Gender, men & $173(37)$ & & & & $45(49)$ & $124(33)$ & $<.01$ \\
\hline Age, yrs & $42 \pm 10$ & $43 \pm 11$ & $41 \pm 9$ & .02 & $41 \pm 9$ & $41 \pm 10$ & ns \\
\hline $\begin{array}{l}\text { Disease duration, } \\
\text { yrs }\end{array}$ & $13 \pm 10$ & $13 \pm 9$ & $15 \pm 12$ & .02 & & & \\
\hline HLA-B27 positive & $232(49)$ & $110(77)$ & $121(52$ & $<.01$ & $47(57)$ & $180(61)$ & ns \\
\hline \multicolumn{8}{|l|}{ Current treatment } \\
\hline DMARD & $261(55)$ & $88(51)$ & $173(59)$ & ns & $41(46)$ & 217 (59) & .02 \\
\hline NSAIDs & $370(78)$ & $126(73)$ & $244(82)$ & .02 & $59(65)$ & 305 (82) & $<.01$ \\
\hline BASDAI & $6.1 \pm 2.1$ & $5.8 \pm 2.3$ & $\begin{array}{c}6.3 \\
\pm 2.0)\end{array}$ & .03 & $5.2 \pm 2.2$ & $6.3 \pm 2.1$ & $<.01$ \\
\hline BASFI & $5 \pm 3$ & $5.1 \pm 2.8$ & $\begin{array}{c}5.4 \\
\pm 2.4)\end{array}$ & ns & $4.7 \pm 2.4$ & $5.5 \pm 2.6$ & $<.01$ \\
\hline $\begin{array}{l}\text { ASAS Health } \\
\text { Index }\end{array}$ & $10 \pm 4$ & $9 \pm 4$ & $10 \pm 3$ & $<.01$ & $9 \pm 3$ & $10 \pm 4$ & ns \\
\hline Currently paid job & $304(64)$ & $69(75)$ & $228(61)$ & .01 & $131(76)$ & $172(58)$ & $<.01$ \\
\hline $\begin{array}{l}\text { Absenteeism, } \\
\text { patients }\end{array}$ & $125(41)$ & $21(30)$ & $101(44)$ & .04 & $28(31)$ & $66(48)$ & $<.01$ \\
\hline $\begin{array}{l}\text { Presenteeism, } \\
\text { patients }\end{array}$ & $202(81)$ & $46(79)$ & $151(83)$ & ns & $81(75)$ & $120(88)$ & $<.01$ \\
\hline
\end{tabular}

Legend: Values are reported as numbers (\%) or mean ( \pm standard deviation, SD).

Acknowledgement: This study was conducted with help of the Chilean spondyloarthritis patient foundation "Espondilitis Chile".

Disclosure of Interests: Sebastian Ibáñez Consultant for: Novartis, Paid instructor for: Bristol Myers Squibb, Speakers bureau: Abbvie, Rianne van Bentum: None declared, Omar Valenzuela Consultant for: Novartis, Paid instructor for: Bristol Myers Squibb, Speakers bureau: Abbvie, Irene van der Horst-Bruinsma Grant/research support from: MSD, Pfizer, AbbVie, Consultant for: Abbvie, UCB, MSD, Novartis, Speakers bureau: BMS, AbbVie, Pfizer, MSD

DOI: 10.1136/annrheumdis-2019-eular.849

\section{THU0387 ENTEROPATHIC ARTHRITIS PATIENTS UNDER BDMARD TREATMENTS HAD FREQUENTLY RADIOGRAPHIC SACROILIITIS: HUR-BIO REAL LIFE RESULTS}

Gözde Kübra Yardımcı, Bayram Farisoğulları, Alper Sarı, Levent Kılıç, Berkan Armagan, Emre Bilgin, Ertuğrul Çağrı Bölek, Omer Karadag, Ali Akdoğan, Sule Apras Bilgen, Sedat Kiraz, Ali İhsan Ertenli, Umut Kalyoncu. Hacettepe University Medical School Internal Medicine, Rheumatology, Ankara, Turkey

Background: Enteropathic spondyloarthritis (eSpA) is one of the diseases in the Spondyloarthritis (SpA) spectrum and occurs in patients with inflammatory bowel disease (IBD). Sacroiliitis is frequently found in patients with IBD and can be overlooked because of focusing on IBD.

Objectives: Aim of this study is to evaluate the general features of eSpA and compare with psoriatic spondylitis (PsA), and ankylosing spondylitis (AS).

Methods: HUR-BIO (Hacettepe University Rheumatology Biologic Registry) is a prospective, single center database of biological treatments since 2005. eSpA patients were enrolled from HUR-BIO registry. Sacroiliitis was defined as modified New York criteria or based on ASAS magnetic resonance imaging criteria. Age and disease duration matched 128 ankylosing spondylitis and 96 psoriatic spondylitis patients were selected as a control group from HUR-BIO database. Demographic, clinical, laboratory, therapeutic data and imaging features were collected from this database: age, gender, age at disease onset, disease duration, type of IBD. Baseline disease activity before the first biologic therapy use was assessed with BASDAI, BASFI, VAS-patient global assessment, ESR and CRP.

Results: HUR-BIO SpA registry included $2576 \mathrm{SpA}$ patients, and 90 (3.5\%) patients had enteropathic arthritis (EA). Sixty four of 90 (71.1\%) patients had sacroiliitis according to modified NY criteria, and these patients were included in the study. Of the 64 patients with eSpA, IBD type was ulcerative colitis (UC) in 34 (53\%) patients, Crohn's disease (CD) in $30(47 \%)$ patients. For eSpA patients, initial biological DMARDs were infliximab in $26(40.6 \%)$, adalimumab in $23(35.9 \%)$, etanercept in $10(15.6 \%)$, golimumab in $4(6.3 \%)$, and certolizumab in 1 patient $(1.6 \%)$ The proportion of bDMARDs were similar with control group. Baseline disease activity were similar between eSpA and control group. However, baseline ESR levels were higher in eSpA than AS $(p=0.037)$ and psoriatic spondylitis $(p=0.001)$, as well. Baseline demographic and clinical features were summarized in Table 1.

Conclusion: Enteropathic spondyloarthrtis was present only a small part of all SpA patients. Sex, SpA family history, and uveitis were different from other $\mathrm{SpA}$ subgroups. Disease activities were similar with other spondyloarthritis, but particularly ESR level was higher in eSpA probably due to bowel disease activity. Sacroiliac and spine involvement seems to be the main reason for starting bDMARD in IBD patients, rather than peripheral arthritis.

Abstract THU0387 - Table 1. Baseline demographic features and disease activity in enteropathic spondylitis, ankylosing spondylitis and psoriatic spondylitis

\begin{tabular}{lcccc}
\hline & $\begin{array}{c}\text { Enteropathic } \\
\text { spondylitis } \\
(\mathbf{n}=64)\end{array}$ & $\begin{array}{c}\text { Ankylosing } \\
\text { spondylitis } \\
(\mathbf{n}=128)\end{array}$ & $\begin{array}{c}\text { Psoriatic } \\
\text { spondylitis } \\
(\mathbf{n}=92)\end{array}$ & $\begin{array}{c}\mathbf{P} \\
\text { value }\end{array}$ \\
\hline Female, $\mathbf{n}$ (\%) & $30(46.9)$ & $50(39)$ & $57(62)$ & $0.004^{*}$ \\
Age, years & $45.0 \pm 12$ & $45.3 \pm 10.6$ & $41.8 \pm 12.2$ & 0.163 \\
Age at diagnosis, years & $35.6 \pm 11$ & $34.8 \pm 10.5$ & $34.1 \pm 11.6$ & 0.763 \\
Disease duration, years & $9.17 \pm 6.9$ & $10.5 \pm 5.4$ & $7.7 \pm 6.9$ & $0.021^{*}$ \\
SpA family history, $\mathbf{n}$ (\%) & $15(23.4)$ & $15(11.7)$ & $31(33)$ & $0.000^{*}$ \\
$\begin{array}{l}\text { Uveitis, } \mathbf{n} \text { (\%) } \\
\text { HLA-B27 } \mathbf{n} \text { (\%) }\end{array}$ & $4(6.3)$ & $28(21)$ & $2(2.1)$ & $0.000^{*}$ \\
$\begin{array}{l}\text { Syndesmophyte } \\
\text { Switching between }\end{array}$ & $11(40.7)$ & $31(59.6)$ & $13(39.4)$ & 0.117 \\
biological drugs, $\mathbf{n}(\%)$ & $21(43.8)$ & $45(35.2)$ & $15(30)$ & 0.355 \\
$\begin{array}{l}\text { Baseline BASDAI } \\
\text { Baseline BASFI }\end{array}$ & $31(48.4)$ & $46(35.9)$ & $36(39.1)$ & 0.246 \\
$\begin{array}{l}\text { Baseline ESR mm/hr } \\
\text { (min-max) }\end{array}$ & $5.7 \pm 2.1$ & $5.4 \pm 1.7$ & $5.8 \pm 1.8$ & 0.271 \\
$\begin{array}{l}\text { Baseline CRP mg/dL } \\
\text { (min-max) }\end{array}$ & $1.6(0-8.6)$ & $3.5(0-9.8)$ & $4.1(0-8.7)$ & 0.577 \\
$\begin{array}{l}\text { Baseline patient global } \\
\text { assessment VAS (min- }\end{array}$ & $60(20-140)$ & $22(2-140)$ & $18(2-95)$ & $0.007^{*}$ \\
max) & & & & \\
\hline
\end{tabular}

Data were given as mean (standard deviation) or median (min-max)

HLAB27 were assessed in 27 eSpA, 52 AS and 33 PSA patients.

Disclosure of Interests: Gözde Kübra Yardımcı: None declared, Bayram Farisoğulları: None declared, Alper Sarı: None declared, Levent Kılıç: None declared, Berkan Armagan: None declared, Emre Bilgin: None declared, Ertuğrul Çağrı Bölek: None declared, Omer Karadag: None declared, Ali Akdoğan: None declared, Şule Apraş Bilgen: None declared, Sedat Kiraz: None declared, Ali İhsan Ertenli: None declared, Umut Kalyoncu Grant/research support from: MSD, Roche, UCB, Novartis and Pfizer, Consultant for: MSD, Abbvie, Roche, UCB, Novartis, Pfizer and Abdi Ibrahim, Speakers bureau: MSD, Abbvie, Roche, UCB, Novartis, Pfizer and Abdi Ibrahim

DOI: 10.1136/annrheumdis-2019-eular.5688

\section{THU0388 CLINICALLY RELEVANT DEFICITS IN PERFORMANCE TESTS IN PATIENTS WITH AXIAL SPONDYLOARTHRITIS (AXSPA) - MORE THAN COLLECTING QUESTIONNAIRES NEEDS TO BE DONE}

Uta Kiltz $^{1,2}$, Eerik Ahomaa ${ }^{1,2}$, Björn Bühring ${ }^{1,2}$, Xenofon Baraliakos $^{1,2}$, Juergen Braun ${ }^{1,2} .{ }^{1}$ Rheumazentrum Ruhrgebiet, Herne, Germany, ${ }^{2}$ RuhrUniversity, Bochum, Germany

Background: Physical function in axial spondyloarthritis (axSpA) usually assessed by the BASFI questionnaire is an established core domain of that disease. There is evidence that self-reported physical function is not equivalent with the actual performance of patients. Physical performance can be assessed as a single task such as grip strength or single stance, or as a generic compound measure such as the short physical performance battery test (SPPB). SPPB comprises a chair rising test, a balance test and gait speed.

Objectives: To investigate which performance tests are most frequently impaired in patients with axSpA.

Methods: Consecutive axSpA patients presenting to our tertiary hospital underwent a standardized assessment including patient and disease characteristics, patient-reported outcomes (ASDAS, BASFI, BASMI, ASAS Health Index (ASAS HI), PHQ-9) and performance tests (SPPB, grip strength and single stance). Structural damage was assessed by mSASSS. Validated cut-offs were used for SPPB, chair rise test, grip strength and gait speed. Impairment of performance tests as well as discrimination between subgroups was analysed.

Results: A total of 200 patients (r-axSpA 65.5\%, nr-axSpA 34.5\%) were included: $69 \%$ males, $44.3 \pm 12.5$ years of age, mean symptom duration 
17.9 years, mean ASDAS 2.5 \pm 1.1 , BASFI $4.0 \pm 2.7$, BASMI $3.5 \pm 1.8$, ASAS HI 7.0 \pm 4.1 , PHQ-9 8.8 \pm 6.2 , mSASSS $(n=157)$ 10.2 \pm 18.8. A total of 132 patients were treated with bDMARDs $(66.5 \%)$. The two most impaired performance tests were repeated chair rising and single stance (Figure 1). An impairment in $\geq 1$ performance test was seen in 87 patients (43.5\%). Patients with impairments, in comparison to those without, were older (48.9 vs. 40.8 years), more often obese (28.7 vs. $26.1 \%$ ), more often depressed (PHQ 12.1 vs. 6.3\%), had lower BASFI values (5.7 vs. 2.8), a decreased ASAS HI (9.6 vs. 5.0), and higher disease activity (ASDAS 3.0 vs. 2.1), all $p<0.01$. The documented impairment in performance was irrespective of medication and structural damage on the group and the individual patient level. The correlation between BASFI and the performance test was moderate for SPPB (0.6), gait speed (0.5), chair rise (0.5) and single stance (0.4), while the correlation between BASFI and grip strength (0.2) and mSASSS (0.2) was rather limited.

Conclusion: In this consecutively recruited relatively young axSpA patients with limitations in physical function and health as assessed by established measures, we found a high prevalence of patients who didn't perform well in tests originally developed for older people. Importantly, a lot of impairment was seen when patients were asked to perform complex tasks requiring coordination and muscle strength. Impairment was present even though most patients received bDMARDs. Since such impairment is potentially influenced by physiotherapeutic interventions, we propose to perform studies to address these deficits. Our data strongly suggest to not only collect questionnaires but also do performance tests to better assess the 'real' physical capacity of patients.

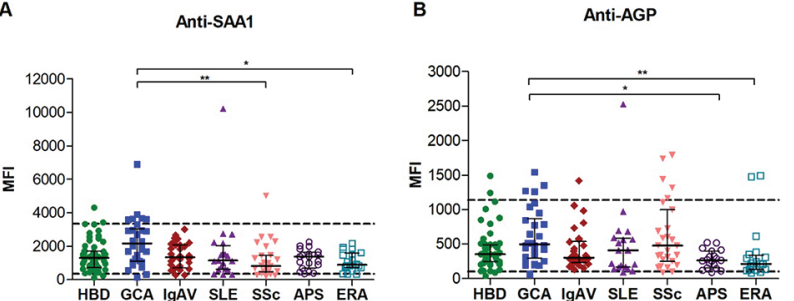

Abstract THU0388 - Figure 1. Performance tests in patients with axSpA *14 patients were not able to perform the test ${ }^{* *} 4$ patients were not able to do a single stance.

Disclosure of Interests:

Uta Kiltz Grant/research support from: AbbVie, Chugai, Eli Lilly, Grünenthal, Janssen, MSD, Novartis, Pfizer, Roche, and UCB., Consultant for: AbbVie, Chugai, Eli Lilly, Grünenthal, Janssen, MSD, Novartis, Pfizer, Roche, and UCB., Eerik Ahomaa: None declared, Björn Bühring Grant/research support from: GE/Lunar and Kinemed., Consultant for: GE/Lunar and Lilly, Xenofon Baraliakos Grant/research support from: AbbVie, Boehringer Ingelheim, BristolMyers Squibb, Celgene, Centocor, Chugai, Janssen, MSD, Novartis, Pfizer Inc, Roche and UCB, Grant/research support from: AbbVie, Pfizer, Merck Sharp \& Dohme, UCB Pharma, Novartis, Consultant for: AbbVie, Bristol-Myers Squibb, Boehringer Ingelheim, Celgene, Chugai, Janssen Biologics, Novartis, Pfizer, UCB Pharma, Galapagos, Speakers bureau: AbbVie, Chugai, Janssen, Novartis, Pfizer, UCB Pharma, Juergen Braun Shareholder of: AbbVie, BMS, Celgene, Chugai, Merck, Novartis, Pfizer, UCB, Grant/research support from: AbbVie, BMS, Celgene, Chugai, Merck, Novartis, Pfizer, UCB, Grant/research support from: Abbott, Bristol Myers Squibb, Celgene, Celltrion, Chugai, Johnson \& Johnson, MSD, Novartis, Pfizer, Roche, UCB Pharma, Grant/research support from: AbbVie, BMS, Celgene, Chugai, Merck, Novartis, Pfizer, UCB, Grant/research support from: Abbvie (Abbott), Amgen, Baxter, Biogen, BMS, Boehringer, Celgene, Celltrion, Centocor, Chugai, Hexal, Janssen, Lilly, Medac, MSD (Schering-Plough), Mylan, Mundipharma, Novartis, Pfizer (Wyeth, Hospira), Roche, Sanofi-Aventis and UCB, Consultant for: Abbvie (Abbott), Amgen, Baxter, Biogen, BMS, Boehringer, Celgene, Celltrion, Centocor, Chugai, Hexal, Janssen, Lilly, Medac, MSD (Schering-Plough), Mylan, Mundipharma, Novartis, Pfizer (Wyeth, Hospira), Roche, Sanofi-Aventis and UCB, Consultant for: AbbVie, BMS, Celgene, Chugai, Merck, Novartis, Pfizer, UCB, Consultant for: Abbott, Bristol Myers Squibb, Celgene, Celltrion, Chugai, Johnson \& Johnson, MSD, Novartis, Pfizer, Roche, UCB Pharma, Speakers bureau: AbbVie, BMS, Celgene, Chugai, Merck, Novartis, Pfizer, UCB, Speakers bureau: Abbvie (Abbott), Amgen, Baxter, Biogen, BMS, Boehringer, Celgene, Celltrion, Centocor, Chugai, Hexal, Janssen, Lilly, Medac, MSD (Schering-Plough), Mylan, Mundipharma, Novartis, Pfizer (Wyeth, Hospira), Roche, Sanofi-Aventis and UCB, Speakers bureau: AbbVie, BMS, Celgene, Chugai, Merck, Novartis, Pfizer, UCB

DOI: 10.1136/annrheumdis-2019-eular.2838

\section{THU0389 \\ A SYSTEMATIC REVIEW OF PREGNANCY OUTCOME IN} ANKYLOSING SPONDYLITIS

Gangarathna Krishna ${ }^{1}$, Anuradha Shajpal ${ }^{2}$, Pip Divall ${ }^{3}$, Manjiri Khare ${ }^{4}$, Arumugam Moorthy'. ' University hospitals of Leicester, Rheumatology, Leicester, United Kingdom; ${ }^{2}$ University hospitals of Leicester, Obstetrics and Gynaecology, Leicester, United Kingdom; ${ }^{3}$ University Hospitals of Leicester, Library, Leicester, United Kingdom; ${ }^{4}$ University hospitals of Leicester, Fetal Maternal Medicine, leicester, United Kingdom

Background: Ankylosing spondylitis (AS) is a chronic, systemic inflammatory arthritis predominantly affecting spine and sacroiliac joints. AS affects young individuals in their third and fourth decades of life. Pregnancy poses challenges in AS patients. Unlike other chronic autoimmune diseases, not much is known regarding pregnancy outcome in AS and a systematic review would help treating clinicians and health professionals. Objectives: Our main objective was to evaluate the pregnancy outcomes in ankylosing spondylitis. We reviewed the management and care related to preconception counselling, antenatal,intrapartum and postpartum period, particularly disease activity,medications and birth outcomes.

Methods: A systematic search of PUBMED and EMBASE was performed. Relevant peer reviewed papers were identified using inclusion criteria which included articles on pregnancy outcomes in AS patients above 16 years. We included only English articles covering systematic reviews, randomized control trials, case reports, observational studies published in medical literature between 1970 and March 2017.We excluded papers discussing general management of AS and articles on other autoimmune diseases and pregnancy. Each author screened the title and abstracts individually based on our criteria. A standardized data collection form was used for assessment of study quality and evidence synthesis. Systematic review was registered in PROSPERO and we followed the PRISMA flow chart.

Results: Our search yielded 544 papers. After initial screening of the titles and abstracts 443 papers were identified of which 42 potentially relevant papers were selected for full text review. 18 papers were finally included. Our initial results are based on individual papers. Zhou et al studied 12 AS patients retrospectively with no adverse outcomes, all had term pregnancies with 5 normal vaginal delivery, 7 caesarean,delivery was based on obstetric reasons. Nai Lee Lui et al observed a reduction in pain in the first trimester, first month postpartum with increase in the second and third trimester and in up to 6 months postpartum. Monika Ostensen et al observed unaltered or aggravated disease symptoms during pregnancy in $80 \%$. Delivery was mainly uncomplicated and was normal in most cases. A postpartum flare during the first 3 months occurred in $90 \%$ of AS pregnancies. Hakan Timur et al did not notice any adverse pregnancy outcomes. Worsening of symptoms was seen in 60$90 \%$ of patients up to 6 months after delivery. Jakobsson et al noticed women with AS had a higher prevalence for several adverse birth outcomes with an influence by both disease severity and comorbidities. Case reports highlighted anaesthetic difficulties during delivery. There was paucity of articles studying the treatment aspects and complications only in pregnant AS patients.

Conclusion: To the best of our knowledge, this systematic review is the first one reviewing the outcome of pregnancy in ankylosing spondylitis. As the studies were heterogeneous, the pregnancy outcome was not consistent. There is paucity of data about pregnancy management for women with AS and further research is needed in this area to guide evidence based management of these pregnancies.

\section{REFERENCE:}

[1] Management of pregnancy with ankylosing spondylitis: Zhou, Qian, et al. : Chinese medical sciences journal $=$ Chung-kuo $\mathrm{i}$ hsueh k'o hsueh tsa chih; Mar 2012; vol. 27 (no. 1); p. 46-49. The effect of pregnancy on ankylosing spondylitis, psoriatic arthritis, and juvenile rheumatoid arthritis: Ostensen, M: American journal of reproductive immunology (New York, N.Y. : 1989); 1992; vol. 28 (no. 3-4); p. 235-237. Pregnancy outcomes in patients with ankylosing spondylitis: a nationwide register study:Jakobsson, Gustav L, et al: Annals of the rheumatic diseases; Oct 2016; vol. 75 (no. 10); p. 18381842. Effect of pregnancy on ankylosing spondylitis: a case-control study: Lui, Nai Lee, et al. : The Journal of rheumatology; Nov 2011; vol. 38 (no. 11); p. 2442-2444

Disclosure of Interests: Gangarathna Krishna: None declared, Anuradha Shajpal: None declared, Pip Divall: None declared, Manjiri Khare Speak ers bureau: Falk forum speaker honorarium in November 2014, Arumugam Moorthy Speakers bureau: Speaker fee from Abbvie, Novartis.

DOI: 10.1136/annrheumdis-2019-eular.5002 